\title{
Outcome of Elastic Stable Intramedullary Nailing (ESIN) for tibia fractures in children.
}

1. FCPS (Ortho)

Associate Professor Orthopedics HITEC-IMS Taxila.

2. FCPS (Ortho)

Medical Officer Orthopedics

Bahawal Victoria Hospital,

Bahawalpur.

3. FCPS (Ortho)

Assistant Professor Orthopedics Bahawal Victora Hospital,

Bahawalpur.

4. FCPS (Radiology)

Assistant Professor Radiology

HBS Medical \& Dental College Islamabad.

5. FCPS (Anesthesiology)

Assistant Professor Anesthesia HBS Medical \& Dental College, Islamabad.

6. FCPS (Anesthesiology)

Associate Professor Anesthesia HBS Medical \& Dental College, Islamabad.

Correspondence Address:

Dr. Kashif Khurshid Qureshi

Department of Orthopedics

HITEC-IMS Taxila Cantt.

khurshidkashif11@gmail.com

Article received on:

27/07/2020

Accepted for publication:

22/09/2020
Kashif Khurshid Qureshi', Imran Anjum², Rao Tayyab Mehmood ${ }^{3}$, Iram Iqbal ${ }^{4}$, Ahmed Jasra ${ }^{5}$, Khalid Z Aslam 6

ABSTRACT... Objectives: To determine outcome in displaced tibial shaft fracture in children treated with elastic stable intra-medullary nailing. Study Design: Case Series study. Setting: Department of Orthopedic, Bahawal Victoria Hospital, Bahawalpur, HBS Medical \& Dental College, Islamabad and HITEC-IMS Taxila Cantt, Pakistan. Period: 2012 to 2019. Material \& Methods: A total of 62 cases of displaced tibial shaft fracture presenting within 7 days of the injury, 6 to 11 years of age of either gender were included. Patients with segmental tibial shaft fractures and open tibial shaft fractures, Gustilo Grade II \& III were excluded. The titanium elastic nails system (TENS) was used in all patients according to the departmental protocols. The sampling technique was consecutive with non-probability. All the patients were followed up in OPD at 2 weeks interval up to 24 weeks after surgery and union of fracture was recorded at 24th week. Results: Mean age was8.55 \pm 1.77 years. Out of these 62 patients, $45(72.58 \%)$ were male and $17(27.42 \%)$ were females with ratio of 2.65:1. Mean duration of fracture was $3.10 \pm 1.95$ days. Mean duration of union in displaced tibial shaft fracture in children treated with elastic stable intra-medullary nailing was $19.40 \pm 3.35$ weeks. Conclusion: This study concluded that use of elastic stable intra-medullary nailing for displaced tibial shaft fracture in children leads to shorter duration of union reliably with minimal complications.

Key words: $\quad$ Elastic Nail, Tibial Fractures, Union Time.

Article Citation: Qureshi KK, Anjum I, Mehmood RT, Iqbal I, Jasra A, Aslam KZ. Outcome of Elastic Stable Intramedullary Nailing (ESIN) for tibia fractures in children. Professional Med J 2021; 28(1):16-21.

https://doi.org/10.29309/TPMJ/2021.28.01.5818

\section{INTRODUCTION}

Tibial shaft fractures are the second commonest cause of hospital admissions in children., ${ }^{1,2}$ the mechanism of injury varies with the age group. Rotational and low energy injuries are common in younger age group while older children and adolescents present with high energy trauma and sports injuries. ${ }^{3}$

Most tibial shaft fractures have been treated conservatively for ages. A recent trend towards management of tibial shaft fractures in children by operative methods has been due to the fact that prolonged immobilization while waiting for union has had negative health implications. Different surgical options have led to a reduced time to union and positive health effects by early integration of the child in to the community. ${ }^{4}$ Manipulation under anesthesia followed by long leg cast, external fixator, plating and intramedullary nailing are the different modalities available.

The results are generally good. Closed reduction with long leg cast is the mainstay of treatment of closed tibial shaft fractures. Secondary malalignment and displacement are not an exception and the patient has to be followed up closely till union to avoid complications. Therefore, in 6-11 years old children a recent trend has been towards early fixation with ESIN. ${ }^{5}$ The results are better with the use of elastic nails when used for tibial or femur shaft fractures between the ages of 6 and 11 years. ${ }^{6}$ Bony union has been variable with time to union between 18 weeks and 21.5 weeks. ${ }^{5,7}$ Local data is scarce for use of ESIN in tibia shaft fracture in children between 6 and 11 years of age. This study would help in providing national data which would be helpful to our 
surgeons.

\section{MATERIAL \& METHODS}

This Descriptive, case series was unducted at Department of Orthopedics, Bahawal Victoria Hosptial, Bahawalpur, HBS Medical and Dental College Islamabad and HITEC Institute of Medical Sciences, Taxila, from March 2012 to June 2019.

The Sampling Technique used was Nonprobability, consecutive sampling.

\section{Inclusion Criteria}

Age

6-11 years.

\section{Gender}

Both males and females.

Diagnosed cases of displaced tibial shaft fractures presenting within seven days of injury.

Closed displaced tibial shaft fracture

\section{Exclusion Criteria}

Open tibial shaft fracture (on clinical examination).

\section{Procedure}

After anesthesia fitness and following surgical protocols, all the children were operated on a radiolucent standard table in the supine position. The entry point for the nail was decided using image intensification to avoid the growth plate. All nails were inserted from proximal to distal with medial and lateral insertion points. The nails crossed each other at fracture site where maximum bend in the nail was created by the surgeon. The fracture was reduced closed and any angulation or displacement was corrected with the help of elastic nails. Postoperatively, cotton and crepe bandage was applied and non-weight bearing ambulation was allowed till callus was evident on $\mathrm{x}$-rays when gradual weight bearing was started. Stiches were removed at two weeks and x-rays were done at two weekly intervals till union. All nails were removed within 18 months of insertion. A check $x$-ray was done after removal of nail and the patient was discharged from care after a month of removal when all was fine.

\section{RESULTS}

Age range in this study was from 6 to 11 years with mean age of $8.55 \pm 1.77$ years. Majority of patients 37 (59.68\%) were between 9 and 11 years of age with male to female ratio of $2.65: 1$.

Mean duration of union in displaced tibial shaft fracture in children treated with ESIN was $19.4 \pm$ 3.35 weeks as assessed with good quality digital $\mathrm{x}$-rays.

\begin{tabular}{|l|c|c|}
\hline \multicolumn{1}{|c|}{ Age (in years) } & No. of Patients & \%age \\
\hline $6-8$ years & 25 & 40.32 \\
\hline 9-11 years & 37 & 59.68 \\
\hline Total & 62 & 100.0 \\
\hline
\end{tabular}

Table-I. \%age of patients according to Age distribution $(n=62)$.

Mean $\pm S D=8.55 \pm 1.77$ years

\begin{tabular}{|l|c|c|}
\hline $\begin{array}{c}\text { Duration of } \\
\text { fracture (in days) }\end{array}$ & No. of Patients & \%age \\
\hline 0-3 days & 38 & 61.29 \\
\hline $4-7$ days & 24 & 38.71 \\
\hline
\end{tabular}

Table-II. \%age of patients according to duration of fracture $(n=62)$.

Mean $\pm \mathrm{SD}=3.10 \pm 1.95$ days

\begin{tabular}{|l|l|l|}
\hline \multirow{2}{*}{ Age (in years) } & \multicolumn{2}{|c|}{ Union Time (in weeks) } \\
\hline 6-8 years & Mean & SD \\
\hline 9-11 years & 19.30 & 2.90 \\
\hline P-value & 19.45 & 3.58 \\
\hline
\end{tabular}

Table-III. Stratification of union time with respect to age groups.

\begin{tabular}{|l|l|l|}
\hline \multirow{2}{*}{ Gender } & \multicolumn{2}{c|}{ Union Time (in weeks) } \\
\cline { 2 - 3 } & \multicolumn{1}{|c|}{ Mean } & SD \\
\hline Male & 19.24 & 3.49 \\
\hline Female & 19.82 & 3.03 \\
\hline P-value & 0.5239 \\
\hline \multicolumn{2}{|c|}{ Table-IV. Stratification of union time with respect to } \\
Gender.
\end{tabular}

\section{DISCUSSION}

Non-surgical treatment of long bone fractures in children has excellent results, with reported union rates of more than $90 \%$ and $100 \%$ full functional recovery. ${ }^{8}$ Occasionally, reduction cannot be maintained due to excessive shortening, or malrotation at the fracture site, making operative intervention necessary. ${ }^{9}$ At other times surgery 
is warranted because of polytrauma, open fracture or compartment syndrome. Previously, external fixators and plate and screw fixation was the only treatment available for unstable fractures. Recently, the use of elastic stable intramedullary nails has dramatically increased with the introduction of variety of nails for pediatric fractures. ${ }^{10}$ The elastic nails are adept for the small canal and can be introduced obliquely to climb up the straight diaphysis.

Elastic stable intramedullary nailing for pediatric fracture management has gained increasing popularity since its introduction in the late 1970s. relatively few modifications have been made to the original technique in the last forty years, which illustrates the sound biomechanical principles and simplicity of the technique, pointed out that poor results after ESIN were typically due to incorrect constructs, incorrect indications and insufficient surgeon training. ${ }^{11}$ initially ESIN use was limited to multiple injury patients or in head trauma where cast or traction was not suitable but gradually the indications have expanded not only to incorporate the diaphysis but extended to the metaphyseal fractures, comminuted fractures, pathologic fractures and fractures of the smaller bones. We conducted this study to study mean duration of union in displaced shaft fractures of tibia treated by ESIN.

In our study the mean duration of union in displaced tibial shaft fractures in children treated with elastic stable intra-medullary nailing was $19.4 \pm 3.35$ weeks. About $84 \%$ of fractures united within 8 weeks and in 10 weeks $100 \%$ of the fractures had united. Our study showed an overall complication in $2(8 \%)$ of the cases. The most common complication with titanium nailing is a palpable implant and was present in $8 \%$ of the patients. Complications like wound infection, knee stiffness were not encountered. All of the cases returned to full power and range of motion of knee within 16 weeks. Our study showed excellent results in 23 (92\%) of the patients and good results in 2 (8\%) of cases.

The study of Gordon JE and workers recorded achievement of bony union in 18 weeks while another study recorded these findings in 21.5 weeks. $^{12}$ In another study, 36 patients have undergone ESIN for diaphyseal tibial fracture. The age range was 5-17 years (mean 12.5 years) at the time of surgery. Of these patients one had distal tibia fracture. The most common mechanism of injury was road traffic accidents and motorbike driving. Five patients presented with open fracture. In 31 patients the fracture was reduced by closed methods, whilst in the other five open reduction was required due to difficulty in reduction and soft tissue interposition. In this group we reported only three minor complications (one asymptomatic protrusion of wire, one skin infection at entry site and one entry site skin irritation). All patients in this group achieved complete radiographic healing at a mean of 7.6 weeks (range 5-12 weeks). ${ }^{13}$

Kubiak et al in 2005 compared elastic intramedullary nails with external fixators for the treatment of fracture tibia in children. In their retrospective study of 31 children, 16 children were treated with elastic stable intramedullary nailing and 15 had external fixation. In the external fixation group, 7 bony complications (2 delayed unions, 3 nonunions and 2 malalignment) and in the ESIN group only 01 bony complication was observed respectively. For union in the external fixation group the mean time period was 18 weeks whereas it was only 7 weeks for the ESIN group. This study showed that intramedullary nailing is superior to eternal fixation. ${ }^{14}$

Sankar et al reported a series of 19 children with tibial shaft fractures treated with ESIN. All patients in their series achieved complete healing at a mean of 11 weeks. At final follow-up, mean angulation was 20 in the sagittal plane and 3 으 in the coronal plane. Five patients complained of irritation at the nail entry site; there were no leg length discrepancies or diaphyseal arrest as a result of treatment. ${ }^{*} O$ 'Brien et al. reported a series of 16 children with tibial shaft fractures treated with ESIN. All patients went on to radiographic healing by an average of 9 weeks. No patients had greater than $10^{\circ}$ of angular deformity at final follow-up, and no clinically significant leg length discrepancies resulted from treatment. ${ }^{15}$ Similarly, 
Goodwin et al. reviewed 19 patients with tibial shaft fractures treated with ESIN. After a mean follow-up of 13 months, all achieved union. Two patients had angular deformities in excess of 10 , and one child developed a clinically insignificant physeal arrest. ${ }^{16}$

In a study, out of 18 children with fracture shaft of tibia 15 had close fracture and 3 had open fracture. All fracture cases treated with flexible intramedullary nailing had good alignment postoperatively. The average age of the patient was 8.2 years (range 6-12 years). Sixteen children had an angulation of 5 to 10 degrees which was acceptable to the age group. The mean time of radiologic union was 13.3 weeks with early callus formation of 4.3 weeks with early callus formation at 4.3 weeks. The average time for full weight bearing was 8.8 weeks. The average hospital stay of the patient was 5.7 days (range from 3 to 16 days). ${ }^{17}$

Study done by Liu $\mathrm{P}$ et al showed the average healing time of 10 weeks and at final follow up all the children had full range of movement, two patients had shortening of the limb of less than $1 \mathrm{~cm}$ but without any problem and there was no case of refracture. ${ }^{18}$ Vallamshetla et al studied 56 unstable fractures in 54 children treated with flexible intramedullary nails. The mean time for union was 10 weeks (range 7-18 weeks). In their study, 2 children (4\%) had leg length discrepancies of less than $2 \mathrm{~cm}$, deep infection occurred in 2 cases, 2 patients with significant combination had some progression of angular deformity. There was one death as a result of polytrauma. $^{19}$

Ahmed EKF et al studied 20 children with fracture of shaft of tibia, 14 close fractures and 6 open fractures from March 2012 to June 2013 treated with intramedullary nails. ${ }^{20}$ the mean age of the patients in the study was 11 . Years (range 5-15 years). In their study 15 (75\%) cases had excellent results and 5 (25\%) cases had satisfactory result. There was no poor result according to Flynn scoring criteria for ESINs. Gordon et $\mathrm{al}^{21}$ retrospectively reviewed 60 diaphyseal tibial fractures managed with flexible intramedullary fixation. They achieved 45 bony unions within 18 weeks (average 8 weeks). In their study 5 patients (11\%) had delayed healing, 2 of them required secondary procedures for union (mean time of 41 weeks).

Srivastava et $\mathrm{al}^{22}$ retrospectively reviewed 24 tibia shaft fractures in 24 patients that were treated operatively by elastic stable intramedullary nailing between 1997 and 2005. Extensive review of all charts and radiographic data was completed at Cincinnati Children's Hospital Medical Centre. There was 8 closed and 16 open fractures. The average union time for all tibia fractures was 20.4 weeks. The average union time for all tibia fractures was 20.4 weeks. The average union time for closed and open fractures was 20.2 and 21.5 weeks respectively. Complications included 2 (8\%) neurovascular, 2 (8\%) infections, 2 (8\%) malunions and 1 (4\%) leg-length discrepancy.

Alam and colleagues have reported excellent results in more than $80 \%$ of cases in their study of 2018 as assessed by the Flynn score. ${ }^{23}$ They also did not have any deformity or limb inequality.

In our study the bone union time was average 4.3 weeks (range from 3-9 weeks), complete radiological union was seen in an average of 13.3 weeks (range from 12-18 weeks) and none of the children had delayed union. It was noted that patients with delayed healing tended to be in the older age group (mean age 14.1 years). We did not take weight of the children into consideration which needs further evaluation to add to the safety of the procedure.

\section{CONCLUSION}

We concluded that the use of elastic nails in 6-11 year old children for tibia fracture led to earlier healing with minimal complications.

Copyright@ 22 Sep, 2020.

\section{REFERENCES}

1. Economedes DM, Abzug JM, Paryavi E, Herman MJ. Outcomes using titanium elastic nails for open and closed pediatric tibia fractures. Orthopedics. 2014 Jul; 37(7):e619-24. 
2. Mäyränpää $M K$, Mäkitie $O$, Kallio PE. Decreasing incidence and changing pattern of childhood fractures: A population-based study. J Bone Miner Res. 2010 Dec; 25(12):2752-9.

3. Chapman J, Cohen J. Tibial and fibular shaft fractures in children. 2014. available at: http://www.uptodate. com/contents/tibial-and-fibular-shaft-fractures-inchildren.

4. Singh P, Kumar R. Pediatric femoral shaft fracture management by titanium elastic nailing; a prospective study of 112 patients. The Internet Journal of Orthopedic Surgery 2012; 19:14336.

5. Srivastava AK, Mehlman CT, Wall EJ. Elastic stable intramedullary nailing of tibial shaft fractures in children. J Pediatr Orthop. 2008; 28:152-8.

6. Sheikh SI, Khan A, Iqbal J. Enders nail for diaphyseal long bone lower limb fractures in children. J Rawal Med Coll 2012; 16(1):25-7.

7. Gordon JE, Gregush RV, Schoenecker PL, Dobbs MB, Luhmann SJ. Complications after titanium elastic nailing of pediatric tibial fractures. J Pediatr Orthop. 2007; 27(4):442-6.

8. El-Adl G, Mostafa MF, Khalil MA. Titanium elastic nail fixation for paediatric femoral and tibial fractures. Acta Orthop Belg 2009; 75:512-520.

9. Sankar WN, Jones KJ, David Horn B. Titanium elastic nails for pediatric tibial shaft fractures. $\mathrm{J}$ Child Orthop 2007; 1:281-286.

10. Helenius I, Lamberg TS, Kääriäinen S. Operative treatment of fractures in children is increasing. A population-based study from Finland. J Bone Joint Surg Am 2009; 91:2612-2616.

11. Shital N. Parikh, MD; Viral V. Jain, MD; Jaime Denning, MD; Junichi Tamai, MD; Charles T. Mehlman, DO, MPH; James J. McCarthy, et al. Complications of elastic stable intramedullary nailing in pediatric fracture management. J Bone Joint Surg Am 2012; 94(24):e184.

12. Anjum R, Raina P, Singh $S$, Hackla $S$, Malhotra $S$. Fixation of Paediatric tibial fractures with TENS; A prospective study. Intl J Adv Res. 2015; 3(5):251-54.
13. Furlan D, Pogorelic Z, Bioc`ic M, Juric I, Budimir D, Todoric $\mathrm{J}$, et al. Elastic stable intramedullary nailing for pediatric long bone fractures: experience with 175 fractures. Scandinavian J Surg. 2011; 100:208-15.

14. Kubiak EN, Egol KA, Scher D. Operative treatment of tibial fractures in children: are elastic stable intramedullary nails an improvement over external fixation? J Bone Joint Surg [Am] 2005; 87-A:1761-8.

15. O'Brien T, Weisman DS, Ronchetti P, et al: Flexible titanium elastic nailing for the treatment of the unstable pediatric tibial fracture. J Pediatr Ortop 2004; 24:601-609.

16. Goodwin RC, Gaynor T, Mahar A. Intramedullary flexible nail fixation of unstable pediatric tibial diaphyseal fractures. J Pediatr Orthop 2005; 25:570576.

17. Onta PR, Thapa P, Sapkota K, Ranjeet N, Kishore A, Gupta M. Outcome of diaphyseal fracture of tibia treated with flexible intramedullary nailing in pediatrics age group; A prospective study. Am J Public Health Res. 2015; 3(4A):65-8.

18. Liu P, Wei Z, Wei $Y X$. Treatment of children-s shaft fracture of tibia and fibula with ESIN fixation. OJPed 2011; 1:9-11.

19. Vallamshetla P, De Silva U, Bache CE, Gibbons PJ. Flexible intramedullary nails for unstable fractures of the tibia in children. An eight-year experience. $J$ Bone Joint Surg Br 2006; 88: 536-540.

20. Ahmed EKF, Zakaria B, Hadhood M, Shaheen A. Management of diaphyseal tibial fracture in pediatric by elastic stable intramedullary nails. Menoufia Med J. 2014; 27:401-406.

21. Gordon JE, Gregush RV, Schoenecker PL. Complications after titanium elastic nailing of pediatric tibial fractures. J Pediatr Orthop 2007; 27: 442-446.

22. Srivastava AK, Mehlman CT, Wall EJ, Do TT. Elastic stable intramedullary nailing of tibial shaft fractures in children. J Pediatr Orthop. 2008; 28(2):152-8.

23. W Alam, FA Shah, V Kumar. Our experience of open tibial shaft fractures treated by intra-medullary flexible nailing in paediatric age group. Pak J Surg 2018; 34(4): 341-344. 


\begin{tabular}{|c|l|l|l|}
\hline \multicolumn{3}{|c}{ AUTHORSHIP AND CONTRIBUTION DECLARATION } \\
\hline Sr. \# & \multicolumn{1}{|c|}{ Author(s) Full Name } & \multicolumn{1}{|c|}{ Contribution to the paper } & Author(s) Signature \\
\hline 1 & Kashif Khurshid Qureshi & Principal author \\
2 & Imran Anjum & Principal researcher \\
3 & Rao Tayyab Mehmood & Co-Author & \\
4 & Iram Iqbal & Co-Author & \\
5 & Ahmed Jasra & Co-Author & \\
6 & Khalid Z Aslam & Co-Author & \\
\hline
\end{tabular}

